\title{
Revitalisasi Kurikulum Muatan Lokal Untuk Pendidikan Karakter Melalui Evaluasi Responsif
}

\author{
Al Musanna \\ Dosen Sekolah Tinggi Agama Islam Gajah Putih Takengon. Aceh Tengah \\ e-mail: (win moes@yahoo.co.id/winmoes78@gmail.com)
}

\begin{abstract}
Abstrak: Kajian ini dimaksudkan untuk mengelaborasi pengembangan kurikulum muatan lokal dengan menggunakan evaluasi responsif sebagai pijakannya. Elan-vital kurikulum muatan lokal di sekolah dimaksudkan untuk meningkatkan relevansi pembelajaran dengan konteks sosial-budaya peserta didik dan diharapkan berperan dalam melestarikan khazanah keragaman budaya yang merupakan soko-guru kebudayaan nasional. Dalam aplikasinya, nilai dan budaya lokal yang menjadi isi pembelajaran di sekolah muatan lokal lebih menekankan transfer dan penguasaan pengetahuan yang mapan (established knowledge). Sehingga reinterpretasi dan revitalisasi kearifan lokal yang diharapkan menjadi basis pendidikan karakter tidak berjalan sebagaimana diharapkan. Karenanya, evaluasi terhadap kearifan lokal dengan mempertimbangkan relevansinya dan melibatkan stakeholders, sebagaimana ditawarkan model evaluasi responsif, diyakini mampu memberi kontribusi dalam mempersiapkan peserta didik dalam menjawab berbagai tantangan. Pembahasan ini dilakukan melalui tinjauan literatur yang relevan sehingga diharapkan mampu memberi kontribusi konseptual dalam pengembangan kurikulum muatan lokal pada masa mendatang.
\end{abstract}

Kata kunci: kurikulum muatan lokal, pendidikan karakter, dan evaluasi responsif

\begin{abstract}
This paper intent to elaborate Local Content Curriculum (LCC) development based on responsive evaluation. The main purpose of LCC is to bridge both school experience and student live experience. Additionally, by introducing local culture from early years to student, its used as an effective tools to conserve diversity of cultural heritage which has exist in Indonesian people. Unfortunately, some research indicated that application of LCC in school tend to emphasize for transfer of knowledge an-sich, and scope of local culture are narrowed. Local value as a lens of community to solve their problem less appreciated in developing LCC. Its cause LCC loss of relevance to prepare student to be an active participant in their community. In this sense, school leaders, teacher, and decision maker in education needs to collaborate with stakeholders to identify the local culture that can be use as foundation in character education by using responsive evaluation.
\end{abstract}

Key words: local content curriculum, character education, and responsive evaluation

\section{Pendahuluan}

Pendidikan dan budaya merupakan dua hal tidak terpisahkan. Bahkan, dalam maknanya yang luas, pendidikan pada berbagai jenis dan jenjangnya merupakan bagian dari kebudayaan (Sukmadinata, 2008: 60; Tilaar, 2000; Pai, 1990: 27). Melalui pendidikan, nilai-nilai sosial budaya ditransmisi dan ditransformasikan kepada peserta didik. Dalam lingkup lebih spesifik, sekolah sebagai salah satu institusi pendidikan terpenting saat ini, tidak hanya dimaksudkan mempersiapkan generasi muda dengan seperangkat keterampilan bertahan hidup (survival), tetapi juga diharapkan mampu mem- bentuk perilaku dan pola pikir peserta didik yang sejalan dengan konteks sosial budayanya.

Dalam praksis pendidikan, nilai dan budaya lokal cenderung menempati posisi periferal. Mainstream pendidikan di negara-negara berkembang masih kurang memberi ruang pada nilai dan budaya lokal. Akibatnya, sebagaimana dikemukakan sejumlah pakar, sekolah memainkan peran dalam alienasi peserta didik dari konteks sosio-kulturalnya. Sehingga ketika menyelesaikan pendidikan formalnya, sebagian besar peserta didik mengalami kesenjangan kultural, di samping kesenjangan akademik, dan okupasional 
(Zamroni, 2000: 37). Pada sisi lain, minimnya apresiasi kebijakan pendidikan terhadap kearifan lokal juga berdampak pada terkikisnya berbagai aspek budaya lokal (Pradipto, 2007). UNESCO dalam sebuah laporannya menyatakan, "...formal education systems have disrupted the practical everyday life aspects of indigenous knowledge and ways of learning, replacing them with abstract knowledge and academic ways of learning. Today, there is a grave risk that much indigenous knowledge is being lost" (Unesco, 2005: 2).

Dalam konteks pendidikan nasional, kesadaran mengenai signifikansi nilai budaya dalam pendidikan nasional telah dikemukakan tokohtokoh pendidikan nasional sejak awal kemerdekaan, tetapi tidak berjalan efektif (Dewantara, 1962: 185；1967; Widianto\&Pirous, 2009；326). Dalam perkembangannya, sejak penghujung tahun 80-an, pemerintah melalui Departemen Pendidikan dan Kebudayaan telah memberlakuan kurikulum muatan lokal di sekolah. Secara legalformal, muatan lokal mengacu pada Surat Keputusan Menteri Pendidikan dan Kebudayaan Nomor 0412/U/1987, yang penjabarannya di tuangkan melalui Keputusan Direktur Jendral Pendidikan Dasar Menengah Nomor 173/-C/ Kep/ M/1987 (dalam Dakir, 2004; 101). Namun dalam praktiknya, keunggulan lokal (local genius) yang merupakan substansi kurikulum muatan lokal belum diberdayakan secara optimal. Lebih dari itu, transmisi dan transformasi nilai-nilai budaya dan keterampilan yang menjadi elan-vital kurikulum muatan lokal cenderung dijalankan tanpa kesadaran mengenai landasan historis dan tuntutan sosial (Drost, 2007: 5; Tilaar, 2007: 221). Hasilnya, sebagaimana ditunjukkan sejumlah penelitian, pembelajaran muatan lokal di sekolah lebih memerankan fungsi pemeliharaan tradisi yang terpisah dari konteksnya. Pembelajaran muatan lokal cenderung lebih menekankan sisi akademis an-sich. Artinya, keberhasilan pembelajaran muatan lokal dinilai berdasarkan pada pencapaian angka prestasi peserta didik. Padahal yang sejatinya menjadi tujuan akhir pembelajaran muatan lokal di sekolah adalah menumbuhkan kesadaran peserta didik untuk memiliki karakter yang unggul yang mencerminkan nilai-nilai luhur yang telah diwariskan secara berkelanjutan. Kearifan lokal sejatinya tidak dipandang sebagai sebuah produk peradaban yang statis atau mapan. Kearifan lokal merupakan produk dinamis yang dihasilkan dari persentuhan kesadaran manusia dengan realitasnya.

Berdasarkan gambaran tersebut, evaluasi terhadap praktik kurikulum muatan lokal sangat diperlukan. Namun evaluasi yang semata-mata bertumpu pada nilai akademis peserta didik, tidak lagi memadai. Diperlukan model evaluasi alternatif, yang lebih melibatkan stakeholder dalam memperkaya isi dan pelaksanaan muatan lokal di sekolah. Tulisan ini bertujuan untuk memberi gambaran mengenai relevansi model evaluasi responsif yang digagas Robert E. Stake dalam pengembangan kurikulum muatan lokal di sekolah, sehingga dapat lebih berfungsi dalam pembentukan karakter peserta didik.

\section{Kajiaan Literatur Kurikulum Muatan Lokal}

Kurikulum muatan lokal telah dimaknai secara beragam. Tirtaraharjda dan La Sula misalnya, sebagaimana di kutip Wasliman (2007: 209) mengartikan kurikulum muatan lokal sebagai, "...suatu program pendidikan yang isi dan media penyampaiannya dikaitkan dengan lingkungan alam, lingkungan sosial, dan lingkungan budaya serta kebutuhan daerah". Yang dimaksud dengan isi adalah materi pelajaran yang dipilih dan lingkungan dan dijadikan program untuk dipelajari murid di bawah bimbingan guru guna mencapai tujuan muatan lokal. Adapun yang dimaksud media penyampaian ialah metode dan berbagai alat bantu pembelajaran yang digunakan dalam menyajikan isi muatan lokal. Isi program dan media penyampaian muatan lokal diambil dan menggunakan sumber lingkungan yang dekat dengan kehidupan peserta didik. Sementara itu, Departemen Pendidikan Nasional (2006: 5), menyatakan, "muatan lokal merupakan kegiatan kurikuler untuk mengembangkan kompetensi yang disesuaikan dengan ciri khas dan potensi daerah, yang materinya tidak dapat dikelompokkan ke dalam mata pelajaran yang ada. Substansi mata pelajaran muatan lokal ditentukan satuan pendidikan disesuaikan dengan karakteristik daerah." Dengan demikian, kurikulum muatan lokal dapat dimaknai sebagai program kurikuler yang dilaksanakan sekolah untuk meningkatkan 
pemahaman peserta didik mengenai lingkungan sosialnya, khususnya mengenai pengetahuan, nilai, dan keterampilan (Arikunto \& Said, 2002: 5).

Keberadaan kurikulum muatan lokal berpijak pada pandangan mengenai inter-relasi pendidikan dan budaya. Perhatian terhadap relasi pendidikan dan budaya telah menjadi salah satu isu krusial dalam ranah pendidikan sejak lama. Ornstein \& Levine (1985: 324) mengungkapkan bahwa budaya merupakan lensa yang memberi kontribusi penting dalam membentuk perspektif seseorang memandang realitas. Pendidikan baik sebagai proses maupun institusi berperan dalam transmisi dan transformasi budaya. Konsep budaya sendiri mencakup ranah yang sedemikan luas yang berperan sebagai perekat kondisi mental, cita-cita dan sebagainya. Dengan demikian, ketika dikaitkan dengan budaya menurut pandangan Taba (1962: 18) pendidikan mempunyai tiga fungsi, yakni sebagai "preservation and transmission of cultural heritage, instrument for transforming culture, and as the means for individual development." Artinya, sekolah sebagai institusi penting dalam masyarakat modern dituntut perannya dalam mempersiapkan peserta didik yang mampu berperan dalam pemeliharaan dan pengembangan nilai-nilai budaya.

Dalam konteks Indonesia, secara konstitusional nilai dan budaya lokal telah mempunyai pijakan yang kokoh (Luthan, 2009). Pasal 32 Undang-Undang Dasar 1945 menyatakan bahwa kebudayaan nasional merupakan pencerminan dan akumulasi dari budaya yang berasal dari berbagai daerah di seluruh nusantara. Pada bagian lain disebutkan, "kebudayaan bangsa ialah kebudayaan yang timbul sebagai buah usaha budinya rakyat Indonesia seluruhnya. Kebudayaan lama dan asli terdapat sebagai puncak-puncak kebudayaan daerah di seluruh Indonesia, terhitung sebagai kebudayaaan Indonesia" (Hidayati, 2009: 116-17). Lebih lanjut, UndangUndang Nomor 20 Tahun 2003 tentang Sistem Pendidikan Nasional Pasal 1 ayat 2, menyatakan, "Pendidikan nasional adalah pendidikan yang berdasarkan Pancasila dan Undang-Undang Dasar Negara Republik Indonesia Tahun 1945 yang berakar pada nilai-nilai agama, kebudayaan nasional Indonesia dan tanggap terhadap tuntutan perubahan zaman" (Depag, 2008: 2).

\section{Pendidikan Karakter}

Pendidikan karakter telah menjadi polemik di berbagai negara. Pandangan pro dan kontra mewarnai diskursus pendidikan karakter sejak lama (Glanzer \& Milson, 2006). Sejatinya, pendidikan karakter merupakan bagian esensial yang menjadi tugas sekolah, tetapi selama ini kurang diperhatikan. Akibat minimnya perhatian terhadap pendidikan karakter dalam ranah persekolahan, sebagaimana dikemukakan Lickona (1991) dalam Education for Character: How Our School Can Teach Respect and Responsibilty, menyebabkan berkembangnya berbagai penyakit sosial di tengah masyarakat. Seyogyanya, sekolah tidak hanya berkewajiban meningkatkan pencapaian akademis, tetapi juga bertanggungjawab dalam membentuk karakter peserta didik. Capaian akademis dan pembentukan karakter yang baik merupakan dua misi integral yang harus mendapat perhatian sekolah. Namun, tuntutan ekonomi dan politik pendidikan menyebabkan penekanan pada pencapaian akademis mengalahkan idealitas peran sekolah dalam pembentukan karakter (Benninga, 2006: 450).

Sebelum dilanjutkan, dipandang perlu mengungkap hakikat karakter (character). Menurut Kupperman (1991: 3), karakter berasal dari bahasa Yunani yang bermakna, "instrument for marking and graving, impress, stamp, distinctive mark, distinctive nature." Berkowitz (dalam Damond, Ed., 2002: 48) mengartikan karakter sebagai, "...an individual's set of psychological characteristics that affect person's ability and inclination to function morally." Karakter merupakan ciri atau tanda yang melekat pada suatu benda atau seseorang. Karakter menjadi penanda identifikasi. Wilhelm (2005: 18), setelah melakukan tinjauan terhadap sejumlah definisi yang diajukan sejumlah pakar, menyatakan, "character can be measured corresponding to the individual's observance of a behavioral standard or the individual's compliance to a set moral code." Dengan demikian, secara sederhana karakter merepresentasikan identitas seseorang yang menunjukkan ketundukannya pada aturan atau standar moral dan termanifestasikan dalam tindakan.

Dalam diskursus pendidikan Islam, karakter mempunyai sinonim dengan akhlak. Akhlak adalah 
jamak dari khuluq yang berarti adat kebiasaan (aladah), perangai, tabi'at (al-sajiyyat), watak (althab'), adab/sopan santun (al-muru'at), dan agama (al-din) (Lemu, 1997). Dalam memberikan definisi terhadap akhlak, salah satu diantaranya yang banyak menjadi rujukan adalah pandangan yang diajukan Ibn Miskawaih dalam Tahdzib alAkhlak. Menurut Ibn Miskawaih, akhlak adalah keadaan jiwa yang mendorong seseorang melakukan suatu perbuatan tanpa memerlukan pemikiran (Suwito, 1995: 18). Dengan demikian, istilah akhlak merujuk pada kondisi mental yang melembaga pada diri seseorang, sehingga menyebabkannya dalam bertindak tidak memerlukan pertimbangan lagi. Dengan kata lain, akhlak merupakan representasi kejiwaaan yang menyebabkan seseorang melakukan atau tidak melakukan sesuatu dengan mudah. Akhlak mencerminkan nilai dan prilaku terpuji (akhlak alkarimah atau akhlak al-mahmudah), maupun prilaku tercela (akhlak al-mazmumah).

Lalu, apakah pendidikan karakter itu? Jawaban terhadap pertanyaan ini tidaklah sederhana. Meskipun istilah pendidikan karakter populer digunakan, mendefinisikannya bukanlah pekerjaan mudah (Peterson \& Seligman, 2004; Nuccy, 2003). Creasy (2008: 3) misalnya mengartikan pendidikan karakter sebagai upaya mendorong peserta didik tumbuh dan berkembang dengan kompetensi berfikir dan berpegang teguh pada prinsip-prinsip moral dalam hidupnya serta mempunyai keberanian melakukan yang 'benar,' meskipun dihadapkan pada berbagai tantangan. Dengan demikian, pendidikan karakter penekanannya tidaklah terbatas pada transfer pengetahuan mengenai nilai-nilai yang baik ansich, tetapi lebih dari itu menjangkau pada bagaimana menjadikan nilai-nilai tersebut tertanam dan menyatu dalam totalitas pikirantindakan (Dimerman, Ed., 2009). Internalisasi nilai dan keteguhan untuk melakukan tindakan nyata yang dipandang benar merupakan manifestasi keberhasilan pendidikan karakter di sekolah.

\section{Evaluasi Responsif}

Evaluasi merupakan salah satu aspek pendidikan. Tinjauan berbagai model dan signifikansi evaluasi telah menarik perhatian berbagai kalangan. Evaluasi tidak hanya ditujukan mengukur efektifi- tas dan efesiensi program, tetapi juga diharapkan memenuhi pertanggungjawaban publik mengenai berbagai upaya untuk memperbaiki program pada masa-masa mendatang (Stake, 2004: 103). Seiring hal tersebut, terjadi perubahanperubahan signifikan dalam kajian evaluasi; baik secara teoritis maupun praktis. Perkembangan baru dalam filsafat konstruktivisme, psikologi kognitivisme dan teori sosiokultural telah memberi kontribusi penting dalam diskursus evaluasi kontemporer (Linn, 2000: 4-15; Shepard, 2000: 4-14; Patton, 2002: 261).

Salah satu model evaluasi yang semakin mendapat apresiasi secara global adalah evaluasi responsif. Meskipun di Indonesia sendiri, evaluasi responsif belum lazim diterapkan. Padahal, model evaluasi ini telah berusia hampir sepertiga abad dan telah menarik perhatian teoritisi dan praktisi evaluasi di berbagai negara, khususnya di Amerika dan Eropa (Abma, 2006: 32; Davis, ed., 1998; Stufflebeam \& Shinkfield, 2007). Menurut Stake, evaluasi responsif merupakan evaluasi alternatif yang memberi perhatian pada stakeholders, "responsive evaluation is an ally of participatory evaluation, organized with and around stakeholder concerns" (Stake \& Abma dalam Mathison, Ed., 2004). Lebih lanjut, Abma mengungkapkan substansi evaluasi responsif terletak pada dialog yang melibatkan stakeholders, sehingga upaya pengembangan program dapat ditingkatkan (Abma, 2006: 31; Abma, 2005: 280).

Untuk memperoleh gambaran mengenai evaluasi responsif, berikut deskripsi singkat tokoh pengembangnya. Evaluasi ini diperkenalkan Robert E. Stake. Stake dilahirkan di Adams, Nebraska tahun 1927. Karir akademisnya dimulai ketika ia mulai menekuni tes dan psikologi di Universitas San Diego tahun 1954. Gelar Doktor psychometrik diperolehnya dari Universitas Princeton tahun 1958 dengan disertasi Learning Curve Parameters, Aptitudes and Achievements. Sejak saat itu, dia mengabdikan diri sebagai dosen dan peneliti di berbagai universitas terkemuka; Teachers College University of Nebraska, University of Connecticut; Central State College of Washington; Harvard University; the University of British Columbia; Universidad do Espirito Santo; the University of East Anglia; dan Simon Fraser University. Saat ini, Stake adalah Professor 
emiritus pendidikan dan menjabat sebagai Direktur Pusat Penelitian Pengajaran dan Evaluasi Kurikulum (Center for Instructional Research and Curriculum Evaluation/CIRCE) di Universitas Illinois (Mathison dalam Mathison, Ed, 2004).

Dalam ranah evaluasi, Stake memberi kontribusi dalam pengembangan dua model evaluasi (countenance dan responsive). Model Countenance bersifat formal, artinya evaluator tidak hanya mengembangkan tujuan, tetapi juga merincikannya menjadi tujuan khusus yang terukur, sebagaimana berlaku dalam pengukuran behavioristik dan kuantitatif (Stake, 1975: 13). Evaluasi countenance terdiri dari 3 (tiga) fase atau tahapan; dimulai dari antecedent (kondisi awal), transaction (implementasi atau ketika proses berlangsung), dan outcome (hasil atau pengaruh pelaksanaan program) (Stake, 1975: 16; Rosa \& Nyre, 1977). Menurut penuturan Stake, ketertarikannya menekuni tes dan evaluasi sepanjang karir akademiknya tidak terlepas dari trend tahun 50an. Pada saat itu, tes sedang menjadi primadona diskursus pendidikan di Amerika. Para politikus dan pengambil kebijakan menempatkan tes sebagai instrumen peningkatkan kualitas pendidikan dan pemberdayaan (emancipatory) peserta didik. Perhatian dan fokus berlebihan pada pengukuran ini dalam pandangan kritisi pendidikan berdampak pada reduksi pengajaran sebatas pada upaya untuk lulus tes, 'teach what you test.' Padahal, hasil tes tidak dapat memberi gambaran kesuksesan seseorang pada masamasa mendatang. Dalam hal ini, Stake (dalam Davies, Ed., 1998: 365) mengutip pandangan pengkritik mainstream tes menyatakan, "...such test scores did not correlate well with success in later work, with practical ingenuity, aesthethic sensitivity, raising a family, being a good citizen, or becoming an effective teacher. And many of the people who became good at these other things found life harder because their test score suggested their aspirations were less worthy of support."

Faktor lain dikembangkannya evaluasi responsif adalah semakin meluasnya konstruktivisme yang bersumber dari pragmatisme. Dalam aplikasinya, istilah konstruktivisme sendiri digunakan dalam pemetaan aliran dalam filsafat, psikologi, dan teori belajar. Dalam perspektif konstruktivisme, realitas tidaklah terbentuk secara final dan tunggal. Pemahaman realitas di bangun secara berkelanjutan dan melibatkan sisi objektif dan subjektif pengamat, "... a core notion of constructivism is that individuals live in the world of their own personal and subjective experiences. It is the individual who imposes meaning on the world, rather than meaning being imposed on the individual" (Karagiorgi \& Symeou, 2005; 18). Sehingga dalam mengungkap realitas sosial, keterlibatan yang intensif antara pengamat dengan yang diamatinya mutlak diperlukan (Guba \& Lincoln, 1981).

Perkembangan evaluasi responsif juga tidak terlepas dari fenomenologi dan hermenetika. Fenomenologi menempatkan relasi subjek-objek menjadi lebih kompleks. Menurut perspektif ini, hakikat pengalaman (Life-world atau lebenswelt) dapat dimaknai melalui perhatian terhadap keterlibatan pelaku dalam konteks sosio-kulturalnya. Dalam konteks pendidikan, fenomenologi digunakan untuk memperoleh pemahaman mengenai substansi suatu kegiatan atau peristiwa dari sudut pandang pelaku. Peneliti, evaluator atau pengamat menempatkan diri tidak sebagai otoritas otonom dalam menjelaskan hakikat fenomena yang diamati. Dalam menganalisis makna pendidikan misalnya, dialog yang intensif perlu dilakukan untuk menggali substansi persoalan dan kebermaknaannya dari sudut pandang partisipan atau pelaku. Selain itu, melalui hermenetika, yang memposisikan manusia sebagai penafsir (interpreter) aktif terhadap realitas, pemaknaan dipandang sebagai proses menjadi. Pemaknaan terwujud melalui proses dialogis antara subjek dan objek, yang keduanya saling mempengaruhi. Dalam kaitan ini, budaya dan nilai-nilai serta konteks sosio-kultural memainkan peran penting membentuk perspektif dan pandangan seseorang terhadap realitas (Abma, 2006: 32).

Selanjutnya, tinjauan diarahkan pada karakteristik evaluasi responsif yang disampaikan Stake pada Konfrensi Trend Baru Evaluasi yang diselenggarakan di Goteborg, berjudul "Program Evaluation: Particularly Responsive Evaluation." Stake (1975: 1) memulai uraiannya mengenai realitas dan perkembangan baru dalam evaluasi. Menurutnya, kompleksitas pendidikan dan tantangan kehidupan manusia memerlukan tinjauan berkelanjutan untuk menyelesaikannya. 
Kemajuan ilmu pengetahuan telah memberi kontribusi menyelesaikan sejumlah persoalan, namun tidak dipungkiri sejumlah alternatif pemecahan justru menimbulkan masalah baru. Demikian pula halnya dalam evaluasi. Menurut Stake (1975: 13) setidaknya terdapat dua model dominan evaluasi; Pertama, evaluasi yang menekankan pada kebakuan dan struktur yang ketat, Fokus evaluasi ini adalah menilai relevansi program dengan tujuan yang telah ditetapkan atau dalam istilah Stake diklasifikasikan sebagai pendekatan evaluasi pre-ordinate. Pendekatan evaluasi ini mempunyai karakteristik tujuan spesifik, tes objektif, standar baku, laporan penelitian yang ketat. Berbanding terbalik dengan itu, evaluasi responsif bertumpu pada komunikasi alamiah. Dalam model evaluasi ini pihak yang terlibat; baik evaluator maupun stakeholders melakukan interaksi untuk melakukan penilaian terhadap kebermaknaan sebuah program atau peristiwa. Dalam pandangannya, evaluasi responsif bukanlah sesuatu yang baru. Dalam kehidupan sehari-hari, manusia mempraktikan model penilaian yang berpijak pada pilihan-pilihan subjektif dan tidak selalu merupakan produk berpikir rasional an-sich. Dalam pendidikan, tujuan pendidikan tidaklah selalu terukur, misalnya dalam hal ketuntasan, kemampuan dan sikap peserta didik. Makna pendidikan sesungguhnya melampaui indikator-indikator parsial tersebut (Stake, 1975: 12).

Secara konseptual evaluasi responsif mempunyai karakteristik yang berbeda dengan evaluasi konvensional. Sisi informal dari evaluasi responsif dan terwujudnya jalinan komunikasi intensif dan akrab (rapport) antara evaluator dan stakeholders merupakan bagian mendasar dalam evaluasi ini. Stake (1972: 2) menyatakan evaluasi dikatakan responsif apabila memenuhi kriteria: "(1) if it orients more directly to program activities than to program intents, (2) if it responds to audiens requirements for information, and (3) if the different value-perspectives present are referred to in reporting the success and failure of programs". Peranan nilai juga merupakan hal baru dalam evaluasi ini, yang sebelumnya dipandang subyektif yang harus dihindari, sebab evaluasi dipandang sebagai kegiatan yang bebas-nilai, value free.

Hal yang juga membedakan evaluasi ini dengan evaluasi konvensional terletak pada relasi evaluator dan evaluan (stakeholders). Evaluator tidak diposisikan sebagai orang luar, out-siders, yang tugasnya melakukan perbandingan antara sejumlah kriteria dengan praktik di lapangan. Sebagaimana ditegaskan Abma (2006: 33) evaluasi dimaknai sebagai, "...a conversational process of rendering judgement between groups whoses interests are at stake in the evaluation." Dalam evaluasi ini, relasi sosial antara stakeholders dan evaluator, serta antara sesama stakeholders bersipat terbuka, saling menghargai, dan simetris. Partisipan tidak diposisikan subordinate, tetapi setara sehingga memungkinnya terjadinya proses dialogis. Sebagaimana dikemukakan Abma (2006: 35), "the evaluator does not act an expert or judge who stand above other parties, but rather as a partner and collaborator." Dalam evaluasi responsif, peran evaluator lebih dekat berorientasi pada klien, istilah yang secara prinsip mengacu pada stakeholders. Relasi evaluator dan evaluan bersifat interaksionis dan kemitraan (partnership). Dalam hal ini, evaluator berperan sebagai interpreter, guru, fasilitator. Mengenai hal ini, Abma (2006: 34) menjelaskan:

"...as interpreter, the evaluator has to endowmeanings to issues. The role of educator refers to the creation of understanding by explicating various experiences to involved groups. Facilitator refers to the organization of the dialogue and the creation of required conditions. As Socratic guide, the evaluator probes into taken-for-granted ideas, final truths, and certainties and brings in new perspectives."

Penyusunan rencana evaluasi responsif bersifat fleksibel. Artinya, selama proses berlangsung, umpan balik dan perbaikan yang diperlukan dilakukan secara berkelanjutan. Untuk menghindari kesimpangsiuran dalam pelaksanaan evaluasi, Stake menggunakan istilah events, dibandingkan phases. Evaluasi responsif terdiri dari dua belas peristiwa atau events. Masingmasing peristiwa dapat melampaui atau berbalik ke peristiwa sebelumnya, sepanjang hal tersebut diperlukan. Adapun events dalam evaluasi responsif adalah:

"Talk with clients, program staff, audiences; indentify program scope; overview program 
activities; discover purposes, concerns; conceptualize issues, problems; identify data needs, re: issues; select observers, judges, instrument-if any; observe designated antecedents, transactions, and outcomes; thematize: prepare portryals, case studies; winnow format for audience use; assemble formal reports-if any" (Stake, 1975: 21).

Dalam perkembangannya, Guba dan Lincoln (1990) melakukan modifikasi evaluasi responsif dan menamakannya evaluasi generasi keempat, Fourth Generation Evaluation. Dalam penyederhanaan yang dilakukannya, Guba dan Lincoln (1990: 8) mengklasifikasikan tahapan evaluasi ini menjadi empat; "1) initiating and organizing evaluation; 2) identifying key issues and concerns; 3) gathering useful information; 4) reporting results effectively and making recommendations (2003: 563). Curran (2003: 54) Pawan \& Thomalla (2007: 54) menyederhanakan tahapan evaluasi responsif menjadi lima (identifikasi dan konsultasi dengan stakeholders; konsultasi dengan stakeholders berkenaan dengan analisis data; identifikasi standar dan kriteria evaluasi; desain dan implementasi metodologi evaluasi; serta analisis data dan penyusunan laporan).

\section{Relevansi Evaluasi Responsif dalam Pengembangan Muatan Lokal}

Seiring momentum peningkatan perhatian terhadap revitalisasi nilai dan budaya lokal dalam diskursus pendidikan global, inovasi kurikulum muatan lokal menjadi semakin signifikan (Hooley, 2009). Di Amerika Serikat misalnya, berbagai pandangan mengenai pendidikan multikultural serta apa yang dikenal dengan Culturally Responsive Schooling semakin mendapat perhatian (Castagno \& Brayboy, 2008). Dalam artikulasinya, pendidikan berbasis nilai lokal termanifestasikan melalui refomulasi kebijakan pendidikan, pendidikan guru, penggunaan bahasa daerah, dll. (Deyhle, et.al., 2008; Semali \& Kinchelo, 1999). Revitalisasi muatan lokal merupakan salah satu upaya sinergi antara sekolah dan masyarakat. Revitalisasi nilai-nilai budaya lokal muncul sebagai tanggapan di tengah meluasnya keresahan terhadap dampak globalisasi (Mapajanti: 2005). Perkembangan secara massif budaya pop, popular culture, dipandang telah berdampak dan memberi ancaman seirus terhadap berbagai aspek budaya lokal (Strinati, 2007). Dalam hal bahasa misalnya, beberapa penelitian menunjukkan, peran bahasa lokal sebagai identitas kultural mengalami penurunan signifikan. Hal ini membawa implikasi terhadap aspek-aspek budaya lainnya. Sebab, sebagaimana dikemukakan Deyhle, Swiser, et.all., "...language death essentially means the real loss of culture, traditions, and religion" (2008: 6).

Seiring dengan intensitas diskursus pendidikan karakter, upaya menemukan otensitas kearifan lokal yang berkembang di masyarakat. Sebab, kesepatakan mengenai nilai-nilai ideal yang ingin dikembangkan, dalam hal ini kearifan lokal yang menjadi konten kurikulum mutan lokal dapat dijadikan sebagai titik berangkatnya. Swasono (dalam Widianto,Pirous, Mulia, Ed., 2009: 217) menegaskan, "tugas mendesak yang harus segera dilakukan adalah agar berbagai kearifan dan praktik budaya lokal yang positif bagi pembangungan karakter bangsa dapat digali, diangkat sebagai suatu kekuatan bagi pembangunan manusia Indonesia." Menjadi tanggung jawab berbagai pihak untuk memberi kontribusi dalam revitalisasi nilai dan budaya lokal yang sejalan dengan tuntutan dan permasalahan kontemporer. Hunter (2000: 15) dalam The Death of Character: Moral Education in Age of Without Good and Evil menyatakan, karakter selalu terkait konteks sosial. Setiap komunitas mempunyai penekanan mengenai karakter-karakter tertentu yang dipandang penting ditransformasikan (lihat Sternberg \& Grigorenko, 2004; Nakaya, 2004).

Karakter dibentuk dari akumulasi rentang pengalaman dan interaksi yang melibatkan berbagai pihak. Lickona (1991: 76), mengungkapkan sinergi orang tua, guru, tenaga kependidikan, dan kepala sekolah dalam pembentukan karakter peserta didik mutlak diperlukan. Hanya dengan demikian akan terbentuk iklim atau atmosfer sekolah yang kondusif bagi persemaian nilai-nilai luhur yang disepakati. Stein, et.al, (2000) dalam Connecting Character to Conduct: Helping Student to Do Right Thing menunjukkan sejumlah hasil penelitian mengenai signifikansi iklim sekolah dalam membentuk karakter peserta didik. Dalam hal ini, iklim sekolah yang baik tidak saja berpijak pada prinsif profesional, tetapi juga mempertim- 
bangkan relevansi nilai dan pengetahuan dengan konteks sosialnya (Schoen \& Teddlie, 2008: 132). Lebih dari itu, jalinan kesesuaian antara apa yang diperoleh anak di sekolah dengan realitas yang terjadi di rumah, memberi kontribusi penting dalam pembentukan karakter anak. Creasey (2008: 6) menyatakan, "The students will find the transition between home and school to be much easier if the same values and morals taught at school are also echoed at home, and vice-versa." Dalam kaitan ini, pembentukan karakter sejatinya meliputi tiga hal berikut: mengetahui yang baik (knowing the good), kemauan melakukan kebaikan (desiring the good) dan mendorongnya melakukan tindakan yang baik (doing the good) (Lickona, 1991; Bajovic, Rizzo \& Engeman, 2009: 4)

Berdasarkan paparan tersebut, relasi antara kurikulum muatan lokal dalam pembentukan karakter dan evaluasi responsif dapat diringkaskan sebagai berikut. Kurikulum muatan lokal yang menekankan pada pemeliharaan dan pengembangan nilai dan budaya lokal merupakan landasan pijak yan menentukan dalam pengembangan karakter. Karakter yang merupakan akumulasi kearifan lokal tidaklah statis. Kearifan lokal dapat diungkap melalui interaksi secara intensif dengan stakeholders pendidikan. Pada gilirannya diperoleh model konseptual dan aplikasi pendidikan yang relevan dengan kebutuhan masyarakat. Perhatian pada partisipasi dan keterlibatan stakeholders, serta adanya ruang dimensi sosio-kultural diyakini sangat prospektif dalam meningkatkan kualitas kurikulum (Stufflebeam dalam Stufflebeam, Madaus \& Kellaghan, 2002: 69). Melalui evaluasi responsif, keragaman pandangan lebih dapat diakomodasi dalam memperkaya praksis kurikulum yang berbasis pada kebutuhan stakeholders.

\section{Simpulan dan Saran \\ Simpulan}

Keragaman geografis dan sosiologis Indonesia menuntut dikembangkannya praksis pendidikan yang akomodatif dan apresiatif terhadap keberagaman masyarakat di tanah air. Dalam pusaran kebijakan pendidikan nasional yang lebih demokratis dan desentralistis, keterlibatan stakeholders dalam perumusan, implementasi dan evaluasi semakin penting diperhatikan. Dalam tinjauan historisnya, partisipasi stakeholders dalam evaluasi kurikulum masih kurang mendapat pehatian. Padahal, melalui evaluasi yang memenuhi kriteria ilmiah dan mempertimbangkan sisi kontekstualnya merupakan prasyarat perumusan kebijakan yang lebih baik. Kurikulum muatan lokal yang telah diimplementasikan sejak lama, dalam banyak hal masih menyisakan sejumlah persoalan. Salah satu diantaranya berkaitan relevansinya dengan perubahan sosial dan tuntutan masyarakat. Sehubungan dengan hal tersebut, evaluasi memainkan peran signifikan. Model evaluasi responsif yang menekankan keterlibatan stakeholders secara berkelanjutan, berdasarkan sejumlah penelitian terbukti memberi kontribusi signifikan dalam meningkatkan kualitas partisipasi dan kebermaknaan program atau kegiatan.

\section{Saran}

Pengembangan muatan lokal sebagai basis dalam pengembangan karakter peserta didik sangatlah relevan. Untuk itu penggalian dan revitalisasi kearifan lokal yang terdapat pada setiap komunitas di Indonesia menduduki posisi penting untuk dilakukan. Pada tingkatan implementasinya, sinergi para pengambil kebijakan, untuk membangun kultur yang memungkinkan nilai dan budaya lokal dapat di semai pada level sekolah mutlak diperlukan. Dukungan berbagai pihak dalam mewujudkan iklim yang kondusif bagi enkulturasi nilai dan budaya lokal merupakan prasyarat yang penting dalam keberhasilan upaya ini.

\section{Pustaka Acuan}

Abma, Tineke A. 2005. "Responsive Evaluation: Its Meaning and Special Contribution to Health Promotion" dalam Evaluation and Program Planning, Vol. 28, pp. 279-289

Abma, Tineke A. 2006. "The Practice and Politics of Responsive Evaluation" dalam American Journal of Evaluation, Volume 27, Nomor 1, pp. 31-43

Arikunto, Suharsimi., Said, Asnah., 2002. Pengembangan Program Muatan Lokal. Jakarta: Unversitas Terbuka 
Bajovic, Mira., Rizzo, Kelly., Engeman, Joe, 2009. "Character Education Reconceptualized for Practical Implementation" dalam Canadian Journal of Educational Administration and Policy, Issue 92, 14 Maret 2009

Benninga, Jacquess S. 2006. "Character and Academic: What Good School Do" dalam Phi Delta Kappa, Edisi Februari, hal. 448-453

Berkowitz, Marven. 2002. "The Science of Character Education" dalam Damond, William., Ed. Bringing New Era in Character Education. Stanford: Hoover Institution Press.

Castagno, Angelina E., Brayboy, Bryan McKinley Jones, 2008. "Culturally Responsive Schooling for Indigenous Youth: A Review of the Literature" dalam Review Research in Education, Volume 78, Nomor. 4, hal. 941-993

Creasy. 2008. "What is Character Educaton?" dalam Educational Policy, Volume 3 Nomor 12, hal. 172180

Curran, Vernon. 2003. "Application of Responsive Evaluation Approach in Medical Education" dalam Medical Education, Volume 37, hal. 256-266

Dakir, S., 2004. Perencanaan dan Pengembangan Kurikulum. Jakarta: Rineka Cipta

Damond, William., Ed. 2002. Bringing New Era in Character Education, Standford Hoover Institution Press.

Davis, Rita, Ed., 1998. Proceeding of The Stake Syimposium on Educational Evaluation. Illionis: University Illionis

Departemen Agama. 2008. Undang-Undang Nomor 20 Tahun 2003 Tentang Sistem Pendidikan Nasional. Jakarta: Balitbang Depag.

Departemen Pendidikan Nasional. 2006. Model Mata Pelajaran Muatan Lokal SD/MI/SDLB-SMP/MTs/ SMPLB-MA/MA/SMALB/SMK.Jakarta: Balitbang Depdiknas

Dewantara, Ki Hadjar., 1962. Karja Ki Hadjar Dewantara: Bagian Pertama, Pendidikan. Yogjakarta: Majelis Luhur Taman Siswa

Deyhle, Donna., Swisher, Karen., Steven, Tracy. 2008. "Indigenous Resistance and Renewal: From Colonizing Practices to Self-Determination." dalam Connelly, F. Michael., Fang He, Ming., Philion, JoAnn. [Ed.] The SAGE Handbook of Curriculum and Instruction. California: SAGE Publication.

Dimerman, Sara. Ed., 2009. Character Is Key: How to Unlock the Best in Our Children and in Our Self. Ontario: John Wiley \& Sons Canada.

Drost, D.J., 2007. Dari Kurikulum Berbasis Kompetensi (KBK) sampai Manajemen Berbasis Sekolah (MBS): Esai-esai Pendidikan. Jakarta: Penerbit Kompas.

Glanzer, Perry L., Milson, Andrew J., 2006. "Legislating the Good: A Survey and Evaluation of Character Education Laws in the United States" dalam Educational Policy, Volume 20 Nomor 3, hal. 525-550

Guba, Egon G., Lincoln, Yvonna S., 1981. Effective Evaluation: Improving the Usefulness of Evaluation Results Through Responsive and Naturalistic Approach. San Francisco: Jossey-Bass Publisher.

Guba, Egon G., Lincoln, Yvonna S., 1990. Fourth Generation Evaluation. California: SAGE Publishing Hidayati, Inur., 2009. Undang-Undang Dasar 1945 dan Perubahannya. Jakarta: Indonesia Tera.

Hooley, Neil., 2000. "Reconciling Indegenous and Western Knowing." Makalah disampaikan pada the Annual Conference of the Australian Association for Research in Education, Sydney, 4-7

Desember. Pp. 1-14

Hunter, James Davison. 2000. The Death of Character: Moral Education in an Age Without Good or Evil. New York: Basic Books.

Karagiorgi, Y., \& Symeou, L., 2005. "Translating Constructivism into Instructional Design: Potential and Limitations" dalam Educational Technology \& Society, 8 (1), 17-27.

Kupperman, Joel., 1991. Character. New York: Oxford University Press

Lemu, B. Aisah., 1997. Islamic Tahdhib and Akhlak: Theori and Practice. Kuala Lumpur: Iqra' Foundation. 
Lickona, Thomas., 1991. Educaton for Character: How Our School Can Teach Respect and Responsibilty. New York: Bantam Books

Linn, Robert L., 2000. "Assessmentts and Accountability" dalam Educational Researcher, Volume 29, Nomor 2, pp. 4-16

Luthan, Rusli., 2009. Keniscayaan Pluralitas Budaya Daerah: Analisis Dampak Sistem Nilai Budaya terhadap Eksistensi Bangsa. Bandung: Angkasa

Mapajanti, Amien, A., 2005. Kemandirian Lokal: Konsepsi Pembangunan, Organisasi dan Pendidikan dari Perspektif Sains Baru. Jakarta: Gramedia.

Mathison, Sandra, Ed., 2004. Encyclopaedia of Evaluation. Colorado: SAGE

Nakaya, Ayami, 2004. "Muatan Lokal for Current Problems in the Local Community: A Study of the Subject of Local Life and Environmental Education in Jakarta - PLKJ" dalam Pacific Asian Education, Volume 16, Nomor 2, pp. 38-48

Nuccy, Lary P., 2003. Education in Moral Domain. United Kingdom: Cambridge University Press Ornstein, Allan C., Levine, Daniel U., 1985. An Introduction to The Foundations of Education. Third Edition. Boston: Houghton Mifflin Company

Pai, Yong. 1990. Cultural Foundation of Education. New York: McMillan

Patton, Michael Quin. 2002. "Two Decades of Developments in Qualitative Inquiry: A Personal, Experiental Perspective" dalam Qualitative Social Work, Volume 1, Nomor 3, pp. 261-282

Pawan, Paridah., Thomalla, Theresse Groff. 2007. "A Responsive Evaluation Study of ESL/Spanish Language Service for Newcomers" dalam Journal of Ethnographic and Qualitative Research, Volume 1, hal. 50-65

Peterson, Christoper., Seligman, Martin E. P., 2004. Character Strenghts and Virtues: A Handbook and Classification. New York: Oxford University Press.

Pradipto, Y. Dedi., 2007. Belajar Sejati Versus Kurikulum Nasional: Kontestasi Kekuasaan dalam Pendidikan Dasar. Yogyakarta: Kanisius

Rosa, Clara., Nyre, Glenn F. 1977. The Practice of Evaluation. New Jersey: ERIC Clering House on Test, Measurement and Evaluation.

Schoen, La Tefy., Teddlie, Charles. 2008. "A new model of school culture: a response to a call for conceptual clarity" dalam School Effectiveness and School Improvement, Volume 19, No. 2, Juni 2008, hal. 129-153

Semali, Ladislaus M., Kincheloe, Joe L. 1999. What is Indigenous Knowledge?: Voices from the Academy. New York: Falmer Press

Shepard, Lorrie E.,2000. "The Role Assesment in a Learning Culture" dalam Educational Researcher, Volume 29, Nomor 7, pp. 4-14.

Stake, Robert E. 2004. Standard-Based and Responsive Evaluation. London: SAGE Publishing

Stake, Robert E.,1972. Responsive Evaluation. New York: US Department of Health, Education \& Welfare.

Stake, Robert E., 1975. Program Evaluation: Particularly Responsive Evaluation. Illionis: Center for Instructional Research and Curriculum Evaluation (CIRCE) University of Illionis

Stein, Rita., Richin, Roberta., Banyon, Richard. 2000. Connecting Character to Conduct: Helping Student to do the Right Thing. Alexandria, USA: Association for Supervision and Development Curriculum

Sternberg, Robert J., Grigorenko, Andrey. 2004. Culture and competence: Contexts of life success. Washington: American Psychological Association

Strinati, Dominic. 2007. Popular Culture: Pengantar Menuju Teori Budaya Populer. Terjemahan Abdul Mukhid. Cet. III. Yogyakarta: Jejak

Stuffelbeam, Daniel. L. Madaus \& Kellaghan 2002. "Foundational Models for 21st Century Program Evaluation" dalam Stufflebeam, Madaus, Daniel L., Kellaghan, Thomas. Evaluation Models: Viewpoints on Educational and Human Services Evaluation. Second Edition. Boston: Kluwer Academic Publisher 
Stufflebeam, Daniel L., Shinkfield, Anthoni J., 2007. Evaluation Theory, Models and Applications. San Francisco: Willey\&Sons

Sukmadinata, Nana Syaodih. 2008. Pengembangan Kurikulum: Teori dan Praktik. Cet. Ke-10. Bandung: Remaja Rosdakarya.

Suwito. 1995. "Konsep Pendidikan Akhlak Menurut Ibn Miskawaih", Disertasi. Jakarta: IAIN Syarif Hidayatullah.

Taba, Hilda.,1962. Curriculum Development: Theory and Practice. New York: Harcourt, Brace\&World Inc.

Tilaar, H.A.R. 2000. Pendidikan, Kebudayaan dan Masyarakat Madani. Cet. I. Bandung: Remaja Rosdakarya.

Tilaar, H.A.R. 2007. Mengindonesia, Etnisitas dan Identitas Bangsa Indonesia: Tinjauan dari Perspektif Ilmu Pendidikan. Jakarta: Rineka Cipta.

Unesco, 2005. "Curriculum Themes: Indegenous Knowledge and Sustainability" dalam www. unesco.org. [on line] di akses tanggal 24 Februari 2008

Undang-Undang Dasar Republik Indonesia Tahun 1945 (Amandemen)

Wasliman, Iim., 2007. Modul Problematika Pendidikan Dasar. Bvandung: Sekolah Pascasarjana Pendidikan Dasar Universitas Pendiidkan Indonesia.

Widianto, Bambang., Pirous. Iwan Meulia. Ed. 2009. Perspeektif Budaya. Cetakan I. Jakarta: Rajawali Pers.

Wilhelm, Gretchen Marie. 2005. "A Comparative-Qualitative Research Analysis of Character Education in the Christian School and Home Education Milieu" Thesis. Chedarvile University

Zamroni, 2000. Paradigma Pendidikan Masa Depan. Malang: Bigraf Publishing 